\title{
An Innovative Approach for the Management of Complex Crown Fracture - A Case Report
}

\author{
Anshul Arora ${ }^{1}$, Ashtha Arya ${ }^{2}$, Mandeep S. Grewal ${ }^{3}$, Megha Gugnani ${ }^{4}$, Simran $^{5}$ \\ 1, 2, 3, 4, 5 Department of Conservative Dentistry \& Endodontics, SGT University, Gurgaon, Haryana, India.
}

\section{INTRODUCTION}

A tooth can be broken due to many reasons, out of which deep cervical caries can be the one leading to destruction of the whole buccal surface of the tooth. So, to preserve such kind of tooth, root canal treatment is the ultimate treatment option followed by proper selection of the restorative means of such endodontically treated tooth. endodontically treated tooth (ETT) has loss of tooth structure and changes in physical characteristics. Therefore, proper selection of restoration for ETT is mandatory to maintain almost the same level of strength and regaining its functional abilities. The decision of doing restoration of endodontically treated teeth depends on many factors like the amount of tooth structure remaining, condition of the opposing tooth, etc. In cases of less than $50 \%$ tooth structure remaining post and core followed by crown is the best treatment option. This article showcases a case report of treatment of anterior teeth with deep cervical caries. The posts used in these cases were fiber post which were luted and the core build up was done with ParaCore, which is a glassreinforced composite by Coltene.

Deep cervical caries can lead to destruction of the whole buccal surface of the tooth. So, to preserve such kind of tooth, root canal treatment followed by proper selection of restoration for endodontically treated tooth is mandatory to maintain almost the same level of strength and to regain its functional abilities. This article showcases a case report of treatment of anterior teeth with deep cervical caries.

\section{PRESENTATION OF CASE}

A 35-yrs.-old male patient reported to the Department of Conservative Dentistry and Endodontics at SGT Dental College, Gurugram, with a chief complaint of un-aesthetic smile in right upper front tooth region since 3 - 4 yrs. On doing intraoral examination, deep cervical caries was seen with respect to (w.r.t) 12 and 13 which led to complex crown fracture (Figure 1) and there was no pain on palpation and percussion. Pulp was found out to be non-vital after performing the pulp vitality test. Radiographic examination revealed radiolucency involving enamel, dentin and pulp with no periapical radiolucency. On the basis of all the examinations done, diagnosis was made as pulp necrosis, and treatment plan was made as root canal treatment followed by fiber post and finally crown fabrication.

\section{DISCUSSION OF MANAGEMENT}

On the first visit, local anaesthesia was given. Caries was removed with the help of round and straight burs. Access was gained with endo-access bur by Dentsply and Endo-z bur. An electronic apex locator was used to determine the working length and was confirmed radiographically. The coronal third of the canal was enlarged using orifice enlarger rotary file my M-Pro followed by cleaning and shaping of the root canal with the help of rotary files by M-pro till working length.
Corresponding Author: Dr. Anshul Arora, Department of Conservative Dentistry \& Endodontics Faculty of Dental Sciences, SGT University, Gurgaon, Haryana, India. E-mail: anshularora2586@gmail.com

DOI: $10.14260 /$ jemds/2021/98

How to Cite This Article:

Arora A, Arya A, Grewal MS, et al. An innovative approach for the management of complex crown fracture - a case report. J Evolution Med Dent Sci 2021;10(07):447449, DOI: $10.14260 / \mathrm{jemds} / 2021 / 98$

Submission 06-10-2020,

Peer Review 15-12-2020,

Acceptance 21-12-2020,

Published 15-02-2021.

Copyright (c) 2021 Anshul Arora et al. This is an open access article distributed under Creative Commons Attribution License [Attribution 4.0 International (CC BY 4.0)] 
Intermittent irrigation with $4 \%$ sodium hypochlorite followed by sonic vibrations by endo activator for 10 secs during biochemical preparation was done. The orifice was sealed using a cotton pallet and Cavit-M as a temporary restorative material.

On the second visit, the canal was again cleaned with the help of sodium hypochlorite and then the master-cone radiograph was taken to confirm the length of the gutta percha points. Canals were dried with the help of paper points and then were obturated with the gutta percha points by coating the canal with the bioceramic sealer by applying the sealer on the apical third of the points. The GP points were cut and sealed using heated ball burnisher and was sealed using a cotton pallet and Cavit-M as a temporary restorative material.

On the third appointment, after removing the temporary material and the cotton pallet, the post spaces were prepared using peaso-reamers attached to the micromotor handpiece starting from number 1 and was enlarged till number 3 peaso reamer to remove the gutta percha, leaving $3-4 \mathrm{~mm}$ of the gutta percha (GP) points apically. Corresponding size fiber posts were taken and the length was marked using a permanent pen and was inserted into the canal to check the fit and on reaching the exact length, a radiograph was taken to confirm the length and the fit (Figure 2). Now comes the step of cementing the post and building the core using ParaCore by Coltene. Application of the chemically cured Parabond Adhesive was first done into the post space preparation of the root canal and onto the contact surfaces followed by application of ParaCore directly into the root canal using the root canal tip and finally the fiber post was placed into the canal (Figure 2) and excess was removed. Freehand core buildup was done using ParaCore followed by manual contouring of the core build-up. Finally, the crown preparation (Figure 3) was done and the impression was made and finally the fabricated crown was inserted onto the prepared tooth using luting glass ionomer cement (GIC) (Figure 4).
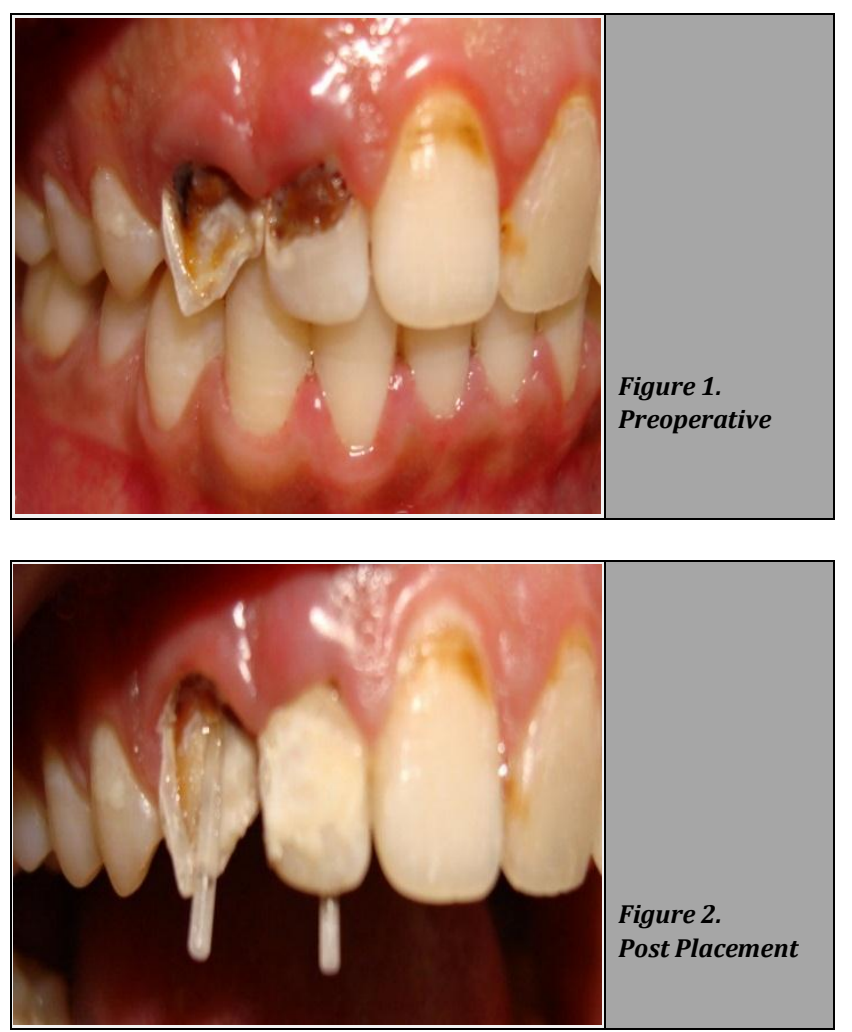
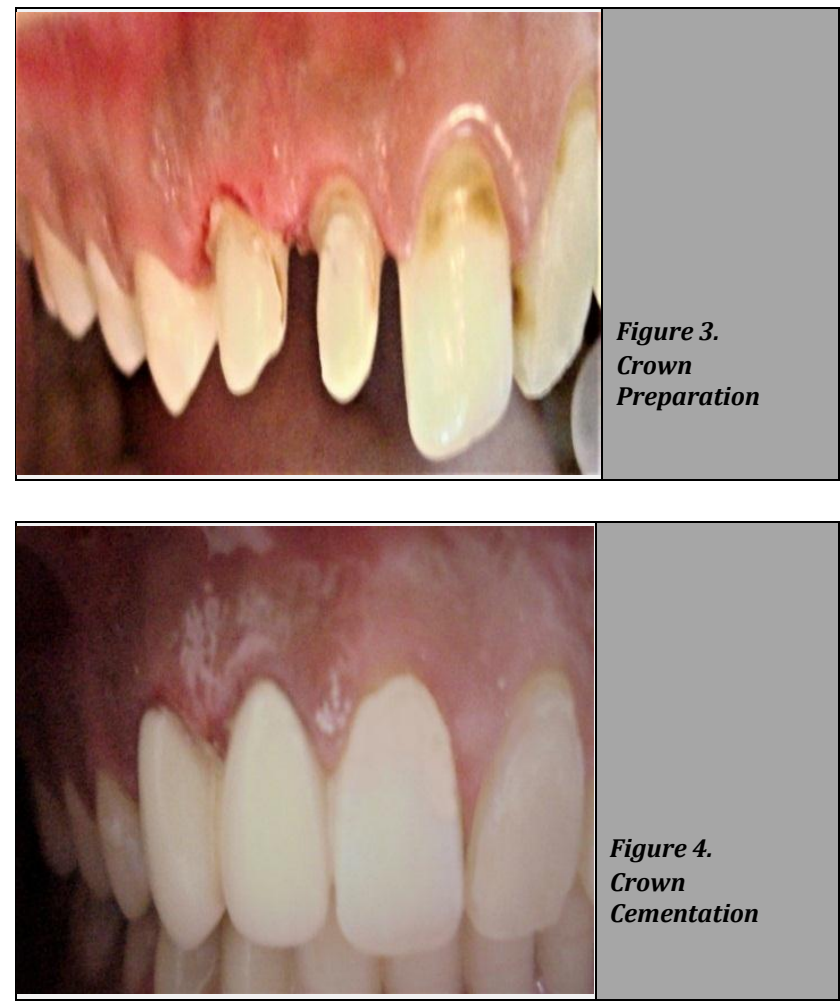

DISCUSSION

An aesthetically beautiful smile is the key to happiness and self-confidence. Explaining the treatment plan to the patient brings high hopes for improvement of the smile but still it all depends on many factors. Earlier, extraction followed by removable or fixed prosthesis was the treatment of choice but by the introduction of posts and core, the scope of saving a tooth increased.

Posts can be classified into many types such as the preformed and custom cast, metallic and non-metallic, stiff \& flexible and aesthetic \& non-aesthetic. ${ }^{1}$ The choice of post design must be according to the biomechanical needs of the remaining tooth structure. ${ }^{2}$ The most important function of the post and core should be the resistant of the forces acting laterally over the tooth and to dissipate those forces over a larger surface area. ${ }^{3}$

The second most important function of the post and core should be an adequate elastic modulus, which should be equal to that of dentin. It helps in equally dissipating the functional stresses preventing endodontic or restorative failures. This is known as "monoblock." A "monoblock" that represents all components of a tooth should have similar elastic-moduli to dentin and allow the components to move, flex and stresses one assembly. This is present in a fiber post. $4,2,5$

Before the introduction of fiber posts, cast post and core was used. But due to many reasons fiber posts were preferred over cast and metal posts. The retention of these posts was affected by post surface area, shape and type of cement used. The retention of metal posts is present due to the presence of grooves, cementation etc. present, but in case of fiber post, bonding is primarily responsible for the retention of these posts. There is more loss of structure in case of cast and metal posts but in case of fiber post, less tooth structure is lost while preparing the "canals." $6,7,8$ 
Metal and cast posts require more clinical and laboratory work whereas it is just one step procedure in case of fiber post. Fiber post is easy to remove without causing any type of trauma and is the most biocompatible material causing no allergic reaction.

The cast or the metal posts fail due to microleakage, root fracture, metal corrosion and more concentration of forces to the areas having lower elastic modulus than posts.

The next most important advantage is the presence of using single material for cementation and core build-up. Using two different core build-up materials causes micro leakage, gapping and no proper bonding between the luting and the core material. 9,10

Financial or other competing interests: None.

Disclosure forms provided by the authors are available with the full text of this article at jemds.com.

\section{REFERENCES}

[1] Pereira JR, de Ornelas F, Conti PC, et al. Effect of a crown ferrule on the fracture resistance of endodontically treated teeth restored with prefabricated posts. J Prosthet Dent 2006;95(1):50-4.

[2] Kaur J, Sharma N, Singh H. In vitro evaluation of glass fiber post. J Clin Exp Dent 2012;4(4):204-9.
[3] Bolla M, Bolla MM, Borg C, et al. Root canal posts for the restoration of root filled teeth. Cochrane Database Syst Rev 2007;1:CD004623.

[4] Shashikala K, Sharma S. Clinical and radiological evaluation of cast metal and quartz fiber posts in endodontically restored teeth. Endodontology 2011;3:37 46.

[5] Dayal C, Dhingra A, Neetika D. A comparative evaluation of fracture resistance of endodontically treated teeth restored by different post system - an vitro study. IOSR Journal of Dental and Medical Sciences 2014;13(12):637.

[6] Uthappa R, Mod D, Kharod P, et al. Comparative evaluation of the metal post and fiber post in the restoration of the endodontically treated teeth. Journal of Dental Research and Review 2015;2(2):73-7.

[7] Reis JMDSN, Oliveira CRM, Reis EGJ, et al. One-step fiber post cementation and core build-up in endodontically treated tooth: a clinical case report. J Esthet Restor Dent 2020;32(1):5-11.

[8] Sharma D, Chaudhary H, Tiwari T. Management of complex crown fracture using fiber post: a case report. Int J Oral Health Med Res 2017;4(3):77-9.

[9] Millar BJ, Deb S. An in vitro study of microleakage comparing total-etch with bonding resin and self-etch adhesive luting cements for all-ceramic crowns. Open Journal of Stomatology 2014;4(3):126-34

[10] Nanda SM, Nanda T, Yadav K, et al. Fiber post \& all ceramic crown- a simple approach to the perfect smile. Sch J Dent Sci 2015;2(3A):247-9. 